\title{
Flume tank characterization of marine current turbine blade behaviour under current and wave loading
}

\author{
Benoît Gaurier ${ }^{a, b, ~ *}$, Peter Davies ${ }^{c}$, Albert Deuff $^{c}$, Grégory Germain ${ }^{a, b}$ \\ a Ifremer, Hydrodynamic \& Metocean Service F-62200 Boulogne-sur-Mer, France \\ ${ }^{\mathrm{b}}$ Univ. Lille Nord de France, F-59000 Lille, France \\ ${ }^{c}$ Ifremer, Materials \& Structures group, F-29280 Plouzané, France \\ *: Corresponding author : Benoît Gaurier, tel.: +33 321995633 ; fax: +33 321995671 ; \\ email address : $\underline{\text { benoit.gaurier@ifremer.fr }}$
}

\begin{abstract}
:
The long term reliability of tidal turbines is critical if these structures are to be cost-effective. Optimized design requires a combination of material durability models and structural analyses which must be based on realistic loading conditions.

This paper presents results from a series of flume tank measurements on strain gauged scaled turbine blades, aimed at studying these conditions. A detailed series of tests on a 3-blade horizontal axis turbine with $400 \mathrm{~mm}$ long blades is presented. The influence of both current and wave-current interactions on measured strains is studied. These tests show that wave-current interactions can cause large additional loading amplitudes compared to currents alone, which must be considered in the fatigue analysis of these systems.
\end{abstract}

\section{Highlights}

This is one of the first papers to describe how wave and current conditions affect tidal turbine blade deformation. There are also very few published data from devices at sea so these results are very important. Results from flume tank tests are presented first, showing how blade deformation depends on current speed. Then results indicate that the wave currents combination will significantly enhance blade loads compared to currents alone.

Keywords: Experimental trials ; Wave and current effects ; Marine current turbine ; Blade deformations ; Hydrodynamic

\section{Introduction}

There is considerable interest in the development of ocean energy conversion systems in order to diversify energy supply. Various reports [1] and [2] have described the potential of ocean energy in Europe. Many wave and tidal 
current energy devices have been developed, and recent reviews describe a large number of different concepts $[3,4,5]$. Tidal energy devices generally involve rotating turbines, and a $1.2 \mathrm{MW}$ prototype device has been operating since 2008 [6]. In order to develop cost-effective tidal energy conversion systems the long term reliability of turbine blades must be guaranteed. Intervention for maintenance or repair will be difficult and costly, and there have already been examples of prototype turbine blade failures during trials at sea [7]. In order to design blades with confidence it is essential to understand the loadings they experience, so that fatigue effects can be properly accounted for. Tests at sea are very expensive, difficult to carry out and the results difficult to analyse, so flume tank testing is generally used for the initial evaluation of new concepts $[8,9,10]$. Several testing tank studies have examined hydrodynamic loads on tidal turbine models, and some data are available $[11,12,13,14]$. These have allowed models to be developed which describe the hydrodynamic response of blades under current loading, based on blade element momentum models [15]. Flow fields around turbines have also been examined in order to characterize wake effects, as this is important in the design of tidal turbine arrays [16, 17, 18, 13, 14]. Models including fluid-structure coupling are also available for propellers [19], based on 3-D boundary element methods coupled with commercial finite element software.

However, there have been few studies to date in which the response of the blades has been measured directly. Results from sea trials are commercially sensitive and rarely available. The authors described some preliminary tests on $300 \mathrm{~mm}$ long instrumented blades under current loads previously, in a study to examine the durability of composite tidal turbine blades [20].

In the present study a set of $400 \mathrm{~mm}$ blades was instrumented with strain gauges in order to measure blade strains directly during flume tank trials. A three-blade turbine was subjected first to current loads at different speeds and then to combined current and wave loads in order to evaluate loading under conditions as realistic as possible at small scale. In this paper, we will first present the materials and methods, before analysing the experimental results obtained on a 1/20 scale model of 1MW 3-blade horizontal axis turbine.

\section{Materials and methods}

In this section, we will first present the experimental facilities in which the trials were carried out. Next, we describe the turbine and the instrumen- 
tation used in this study. Then, we present the different parameters used to characterize the behaviour of the system under current and wave loading.

\subsection{Flume tank}

Tests were performed at the Ifremer (French Research Institute for Exploration and Exploitation of the Sea) wave and current flume tank shown in figure 1 [21]. The dimensions of the flume tank are $L=18 \mathrm{~m}$ long by $W=4 \mathrm{~m}$ wide and $H=2 \mathrm{~m}$ deep. The flow turbulence in the tank is $I_{\infty}=5 \%$ and can be increased to $25 \%$ when removing the flow straighteners. The streamwise flow velocity range is $U_{\infty}=0.1$ to $2.2 \mathrm{~m} / \mathrm{s}$. The wave generator is composed of 8 independent displacement paddles each $0.5 \mathrm{~m}$ wide and $500 \mathrm{~mm}$ deep. It can be easily moved between an upstream or a downstream surface position in order to create waves propagating with or against the current. The capabilities of the wave generator enable the production of regular waves with a frequency range between $f=0.5$ to $2 \mathrm{~Hz}$ and a maximum amplitude of $A=280 \mathrm{~mm}$ with a current up to $0.8 \mathrm{~m} / \mathrm{s}$. Measurements revealed that the resulting reflection coefficient was lower than $12 \%$ for all the usual frequencies and amplitudes. Wave spectrum models (Pierson-Moskowitz, JONSWAP, Bretschneider and others) can be used for the generation of random waves.

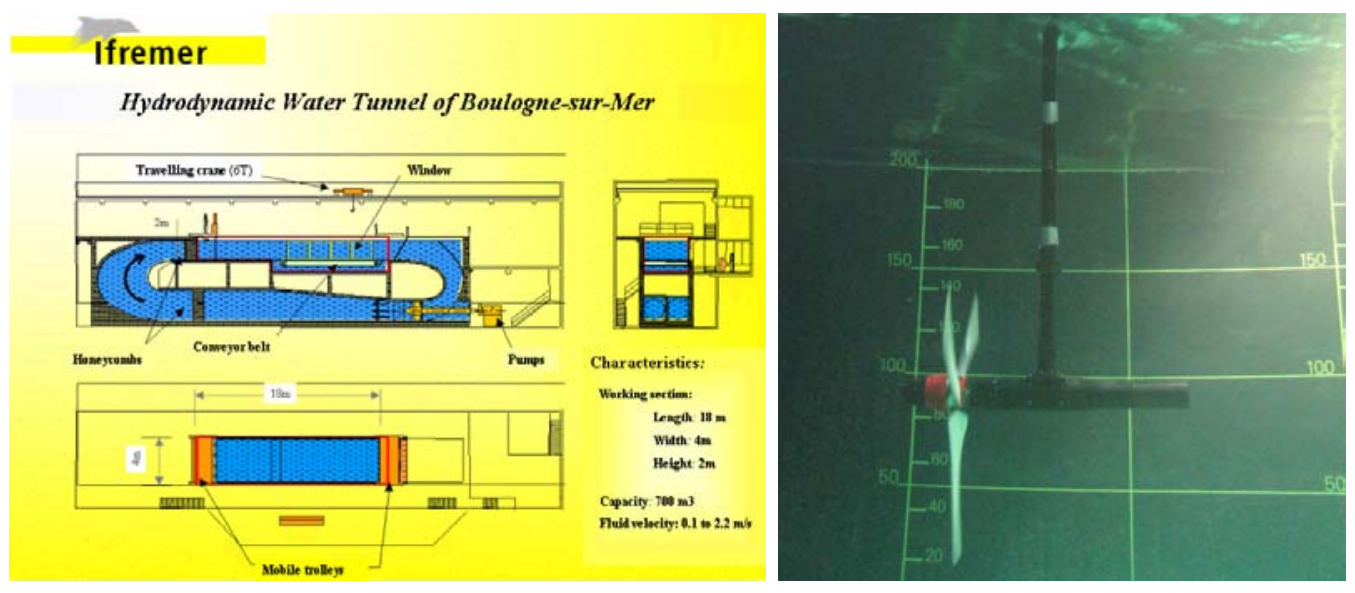

Figure 1: Presentation of the Ifremer flume tank on the left and of the turbine model positioned in the tank on the right

\subsection{Turbine, blades and instrumentation characteristics}

In this study, we used a 3-blade horizontal axis turbine (figure 1) mounted on a six-component load cell in order to measure the hydrodynamic forces 
acting on the system (figure 2). The tri-bladed rotor was connected to a motor-gearbox assembly constituted of gearbox, DC motor, ballast load and motor speed control unit [21], providing active rotor speed control. A torque sensor directly fixed between the rotor and the motor allows to measure the torque in function of the rotation speed. Friction from the axis seal between the rotor and the torque meter is low and neglected. The pitch of the three blades is adjustable but here it was kept constant between tests. The diameter of the rotor tested is $D=2 R=0.9 \mathrm{~m}$, which creates a blockage ratio, percentage of cross-sectional area occupied by the virtual disk swept by the blades, of $\left(\pi R^{2}\right) /(W H)=7.95 \%$ [22]. This ratio is acceptable because it does not modify the incoming flow, according to previous flow measurements. The turbine is positioned in the centre of the depth $H$ of the tank (figure 2 ). Three current velocities are chosen as $U_{\infty}$ input with a low turbulence intensity $I_{\infty}$. For one of these currents, three different regular waves are added in the same direction with frequencies $f$ and amplitudes $A$. The Tip Speed Ratio (TSR) of the turbine is calculated from the rotation speed $\omega$, with the usual form:

$$
T S R=\frac{\omega R}{U_{\infty}}
$$

and varies here from $T S R=0$ to 8 .

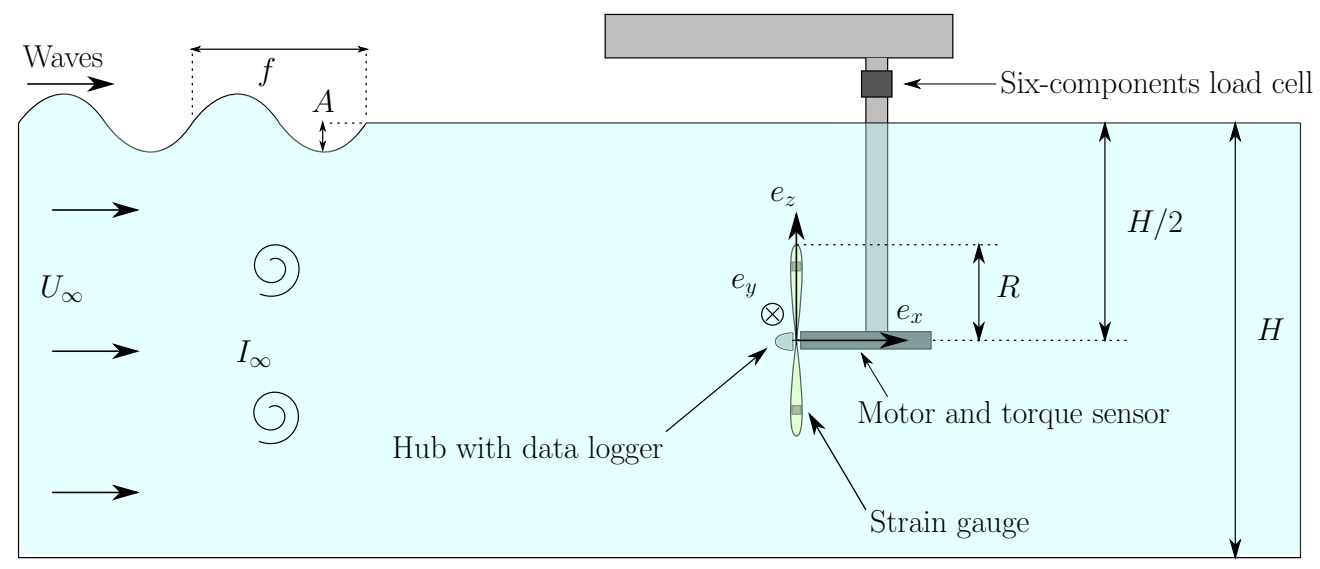

Figure 2: Schematic side view of the tank with the horizontal axis turbine

Three blades, each $400 \mathrm{~mm}$ long, were manufactured by casting a Telene ${ }^{\mathrm{TM}}$ DCPD (dicyclopentadiene) resin into a mould, around a short steel axis which 
enables the blade to be fixed to the turbine hub. The blades were a modified version of the NACA 63418 blade (figure 3). A full description of the blade geometry is available in [23] where the same blade profile was used.

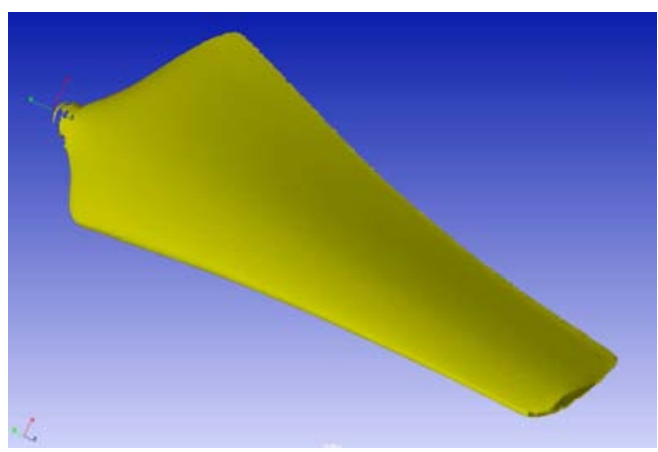

(a) 3D scan of a blade

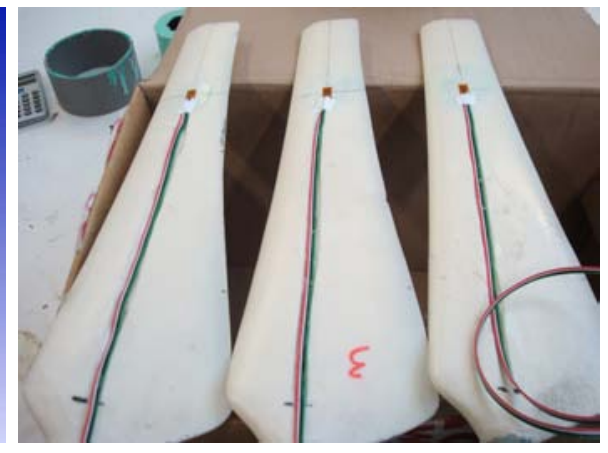

(b) $400 \mathrm{~mm}$ gauged blades

Figure 3: Blades geometry and strain gauges

A strain gauge was bonded to the surface of each blade, at $100 \mathrm{~mm}$ from the tip. Strain gauges were cabled to the data recording system which was an autonomous logger placed in the hub, to overcome any problem of connection between the fixed part of the turbine and the rotating part. With three strain gauges, the memory is sufficient to store signals measured at $100 \mathrm{~Hz}$ during tests lasting up to 45 minutes. Figure 4 shows the blades connected to the logger before immersion. Strain gauges were placed on the front (upstream) face. The strain gauges were calibrated by loading the blades on a test machine with the axis clamped horizontally and applying a fixed $(5 \mathrm{~mm})$ vertical displacement to the tip with a calibrated test machine [20]. During calibration tests it was noted that a one millimeter blade tip displacement corresponded to a 125 microstrain recording. The strain gauge readings were recorded both with the data logger and with an independent calibrated Spyder $8^{\mathrm{TM}}$ data recording system. This allowed the logger output to be checked.

With these gauges, the blades have not a surface as smooth as in [13] or [23]. Results presented in the next sections show that the power coefficient does not seem to be affected, with values close to those observed in previous studies. However, the thrust coefficient directly linked to the drag force is 1.7 times higher for the functioning point $(T S R=4)$. This difference comes from 
the surface of the blade but also from the hub which has a larger diameter here.

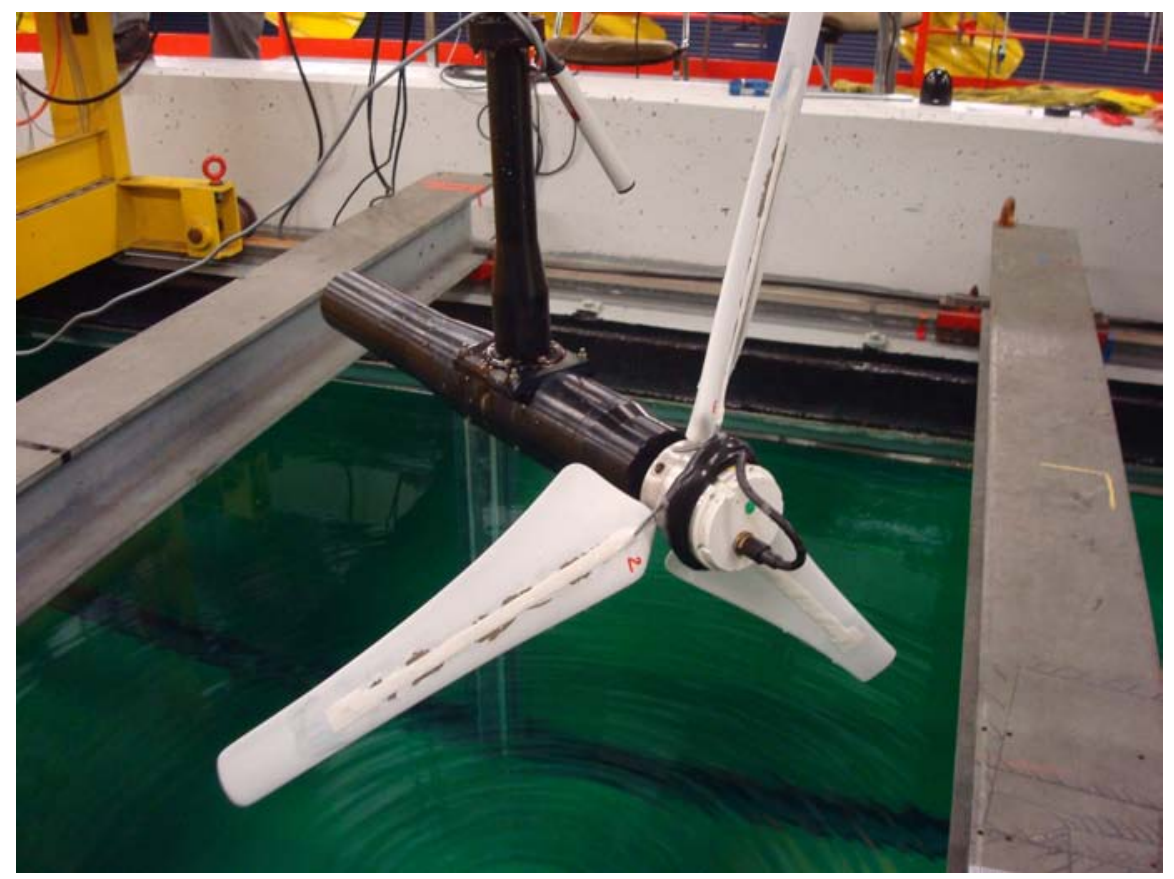

Figure 4: Turbine with 400mm blades and data logger before immersion, shown without nose cover

\subsection{Characteristic parameters}

The behaviour of a marine current turbine can be deduced from the forces and moments measured by the load-cell and the torque measured by the torque sensor. In this study, this last parameter is used to determine the turbine power coefficient $C_{P}$ that assesses its performance and is nondimensionalized to obtain the torque coefficient $C_{Q}$. In addition, the drag force can provide information about the fatigue of the machine and is used for the calculation of the thrust coefficient $C_{T}$.

The power coefficient is defined as the proportion of power $P$ retrieved by the turbine compared to the maximum power available from the incoming flow through the rotor area:

$$
C_{P}=\frac{P}{\frac{1}{2} \rho S U_{\infty}^{3}}=\frac{Q \omega}{\frac{1}{2} \rho \pi R^{2} U_{\infty}^{3}}=\frac{Q}{\frac{1}{2} \rho \pi R^{3} U_{\infty}^{2}} \times T S R
$$


with $\rho$ the water density, $S=\pi R^{2}$ the cross-section area of the turbine and $Q$ the turbine torque.

In a similar way, the torque coefficient is defined as the ratio between the torque developed by the turbine $Q$ and the theoretical torque:

$$
C_{Q}=\frac{Q}{\frac{1}{2} \rho R S U_{\infty}^{2}}=\frac{Q}{\frac{1}{2} \rho \pi R^{3} U_{\infty}^{2}}=\frac{C_{P}}{T S R}
$$

Similarly, the thrust coefficient is defined as the drag force $T$ acting upon the turbine as compared to the kinetic energy of the incoming flow through $S$ :

$$
C_{T}=\frac{T}{\frac{1}{2} \rho S U_{\infty}^{2}}=\frac{T}{\frac{1}{2} \rho \pi R^{2} U_{\infty}^{2}}
$$

\section{Experimental results}

For the different current and wave loadings studied in this work, we present the results obtained for the characterisation of the turbine and the deformations of the blades. For each case, these results are plotted versus the $T S R$. We first present the flow characteristics used to study the behaviour of the turbine and blade deformation. Then we analyse the results for current and wave and current loading.

\subsection{Flow characteristics}

Preliminary measurements are necessary to know precisely the current profiles imposed on the turbine during trials. A series of tests was carried out to measure without the turbine the mean vertical profiles of axial $\left(e_{x}\right)$ and vertical $\left(e_{z}\right)$ velocities on current alone and wave-current interactions; velocity measurements have been performed using a 2 dimensional LDV system. The turbulence intensity of the flow considered in this study is $I_{\infty}=5 \%$. Results from this campaign are presented below, figures 5 and 6 respectively for currents alone of $U_{\infty}=0.60 \mathrm{~m} / \mathrm{s}$ and for waves with the same direction of the current of $U_{\infty}=0.60 \mathrm{~m} / \mathrm{s}$ and $[f=0.5 \mathrm{~Hz} ; A=80 \mathrm{~mm}],[f=0.7 \mathrm{~Hz} ; A=80 \mathrm{~mm}]$ and $[f=0.7 \mathrm{~Hz} ; A=140 \mathrm{~mm}]$.

At full scale, this corresponds to a current of 5.2 knots with wave heights of 3.2 to $5.6 \mathrm{~m}$ crest to trough and periods of 6.4 to $8.9 \mathrm{~s}$, for a $18 \mathrm{~m}$ diameter turbine immersed in mid-depth of $40 \mathrm{~m}$. 


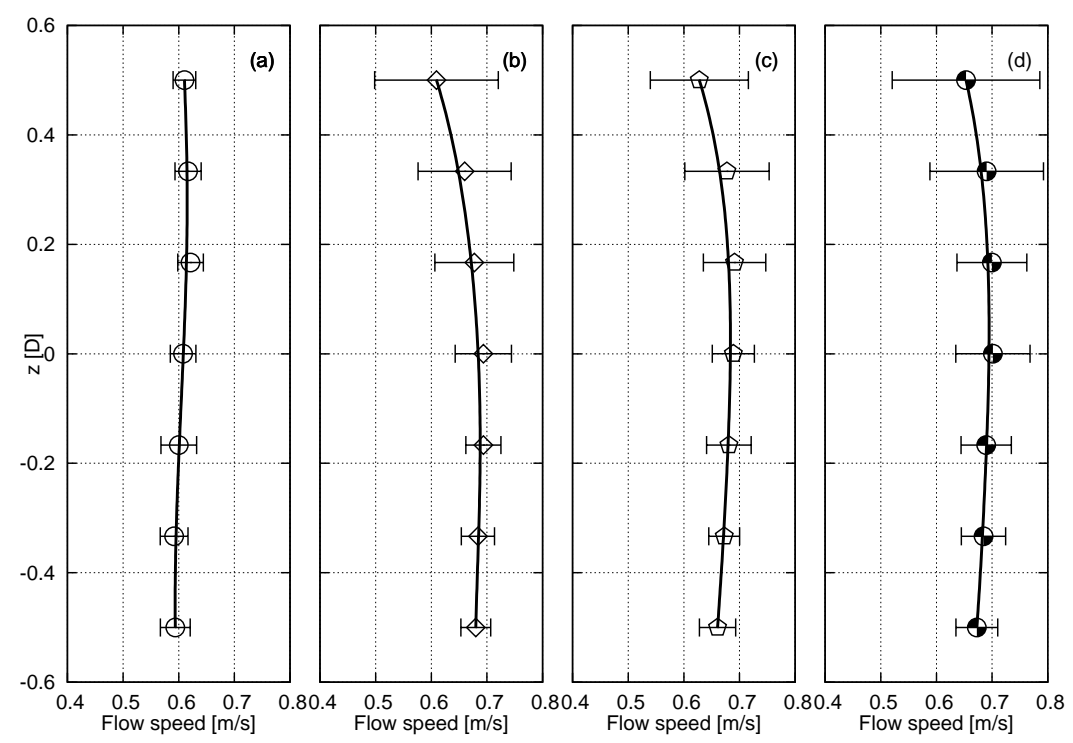

Figure 5: Current and combined wave-current $u$ mean profiles: $U_{\infty}=0.60 \mathrm{~m} / \mathrm{s}$ $\&$ (a) without wave; (b) $[f=0.5 \mathrm{~Hz} ; A=80 \mathrm{~mm}] ;$ (c) $[f=0.7 \mathrm{~Hz} ; A=80 \mathrm{~mm}] ;$ (d) $[f=0.7 \mathrm{~Hz} ; A=140 \mathrm{~mm}]$. Error-bars show standard-deviation.

Figures 5 (a) and 6 (a) show the mean input profiles of the pure current tests for $u$ and $w$ which are respectively the velocity components in the $e_{x}$ and $e_{z}$ directions axis, at the virtual location of the turbine, centred here at $z=0$. Mean velocities observed on these profiles show respectively an axial mean velocity of $U_{\infty}=0.60 \mathrm{~m} / \mathrm{s}$ and mean vertical velocities close to zero. Similar profiles were also obtained at $U_{\infty}=0.40$ and $U_{\infty}=0.80 \mathrm{~m} / \mathrm{s}$. In the following, we will refer to the tests with pure current as $\mathrm{C} 1, \mathrm{C} 2$ and $\mathrm{C} 3$ for the flow velocities at $U_{\infty}=0.40,0.60$ and $0.80 \mathrm{~m} / \mathrm{s}$ respectively.

Figures $5(\mathrm{~b}),(\mathrm{c})$ and $(\mathrm{d})$ and $6(\mathrm{~b}),(\mathrm{c})$ and $(\mathrm{d})$ show the mean input profiles of the current and wave tests for $u$ and $w$. These profiles with waves are different from those with pure current because of the disturbances produced by the wavemaker at the upstream location of the free surface. Globally, the mean-velocity is increasing but a gradient appears along the water column. The mean velocity values are $0.67,0.67$ and $0.68 \mathrm{~m} / \mathrm{s}$ for cases (b), (c) and $(\mathrm{d})$ respectively. In the following, we will refer to $\mathrm{W} \& \mathrm{C} 1, \mathrm{~W} \& \mathrm{C} 2$ and W\&C3 for the tests with $U_{\infty}=0.67 \mathrm{~m} / \mathrm{s}$ and waves $[f=0.5 \mathrm{~Hz} ; A=80 \mathrm{~mm}]$, $U_{\infty}=0.67 \mathrm{~m} / \mathrm{s}$ and waves $[f=0.7 \mathrm{~Hz} ; A=80 \mathrm{~mm}]$ and $U_{\infty}=0.68 \mathrm{~m} / \mathrm{s}$ and waves $[f=0.7 \mathrm{~Hz} ; A=140 \mathrm{~mm}]$ respectively. 


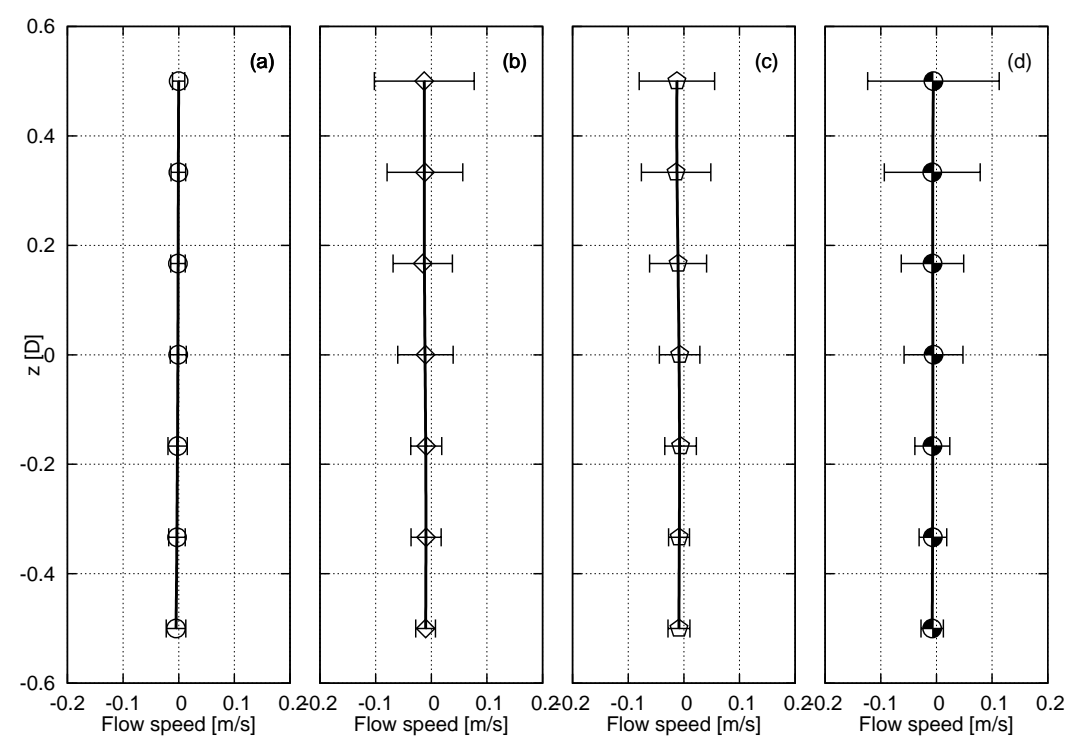

Figure 6: Current and combined wave-current $w$ mean profiles: $U_{\infty}=$ $0.60 \mathrm{~m} / \mathrm{s} \&$ (a) without wave; (b) $[f=0.5 \mathrm{~Hz} ; \quad A=80 \mathrm{~mm}] ; \quad$ (c) $[f=0.7 \mathrm{~Hz}$; $A=80 \mathrm{~mm}] ;(\mathrm{d})[f=0.7 \mathrm{~Hz} ; A=140 \mathrm{~mm}]$. Error-bars show standard-deviation.

The generation of waves modifies the turbulence intensity level of the flow, especially in the upper part (figure 7a). Without waves, it is always around $I_{\infty}=5 \%$, but with waves it can reach $30 \%$ for the highest wave amplitude at the top part of the turbine diameter. The turbulence intensity is calculated with the two dimensions of the laser measurements, according to the following equation:

$$
I_{\infty}=100 \times \sqrt{\frac{u^{\prime 2}+w^{\prime 2}}{\bar{u}^{2}+\bar{w}^{2}}}
$$

where $u=\bar{u}+u_{\text {orb }}+u^{\prime}$ with $\bar{u}$ the mean and $u^{\prime}$ the fluctuating part of the value. The wave orbital velocity $u_{\text {orb }}$ is here extracted from the calculation of the fluctuating part of the velocity components.

The choice of a $I_{\infty}=5 \%$ of turbulence intensity is debatable, especially because recent measurements show that sea profiles can include higher turbulence levels $[8,9]$. However, this is a first study, and future work with higher turbulence levels will follow. The possibility to adjust the turbulence level of the flow ( 5 or $25 \%$ ) is of great interest for the study of wake interactions and turbulence effects on marine current turbines [13] and can be used for 
combined trials under waves and current.

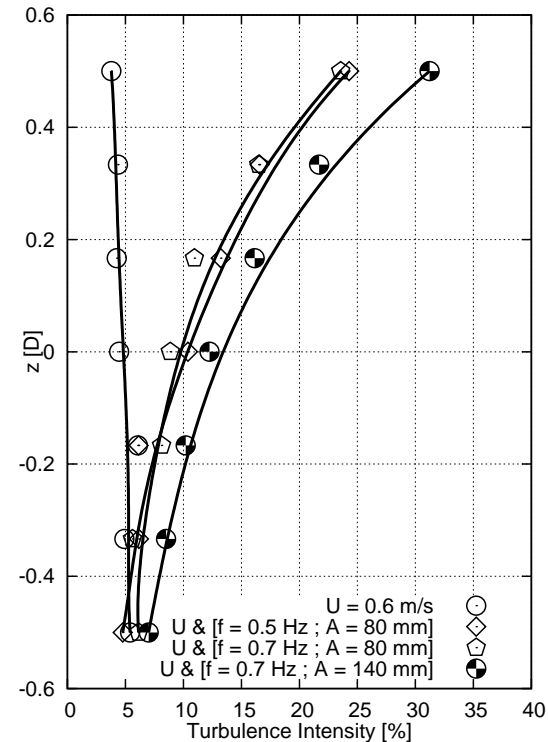

(a) Turbulence intensity: $I_{\infty}$

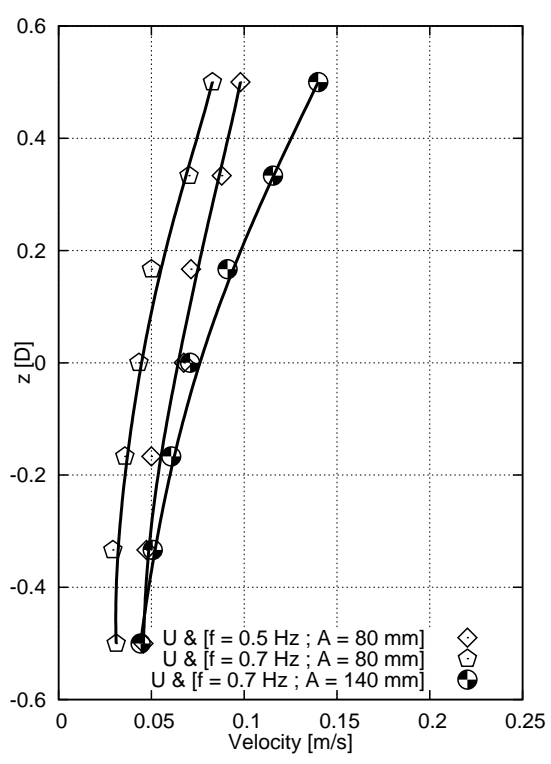

(b) Wave orbital velocities: $u_{\text {orb }}$

Figure 7: Wave and current characteristics

Wave orbital velocities (figure $7 \mathrm{~b}$ ) show three different profiles for each wave condition. These velocities are quite small compared to the current intensity but affect it over 10 to $20 \%$ of the depth. They create an alternating unsteady component of the velocity with a vertical gradient.

In the following section, we first detail the results obtained for the current alone: cases $\mathrm{C} 1, \mathrm{C} 2$ and $\mathrm{C} 3$ before considering the current and wave loading: $\mathrm{W} \& \mathrm{C} 1, \mathrm{~W} \& \mathrm{C} 2$ and $\mathrm{W} \& \mathrm{C} 3$ in order to compare both kinds of loading conditions.

\subsection{Response under current solicitations}

The power coefficient obtained for the tests with pure current (figure 8a) shows a maximum of 0.4 for a tip speed ratio between 4 and 5 . That means that about $40 \%$ of the total available power is retrieved by the turbine for these TSR. This result is in agreement with previous tests performed with the same blade geometry but smaller diameter [13]. This result is not 
dependent on the current velocity because the three curves, obtained for configurations $\mathrm{C} 1, \mathrm{C} 2$ and $\mathrm{C} 3$, are superposed.

For the highest TSR slight differences appear, and the higher the velocity the higher the $C_{P}$. For example, there is a $15 \%$ difference between $U_{\infty}=0.4 \mathrm{~m} / \mathrm{s}(\mathrm{C} 1)$ and $U_{\infty}=0.8 \mathrm{~m} / \mathrm{s}(\mathrm{C} 3)$. This could be explained by the difference of the Reynolds numbers between the three studied cases [24, 25]:

$$
R e=\frac{U_{\infty} R}{\nu}
$$

which are equal to $1.8 \times 10^{5}$ for $\mathrm{C} 1,2.7 \times 10^{5}$ for $\mathrm{C} 2$ and $3.6 \times 10^{5}$ for $\mathrm{C} 3$.

The standard-deviation of the power coefficient is quite constant and remains below $5 \%$ for every $T S R$ and velocity.

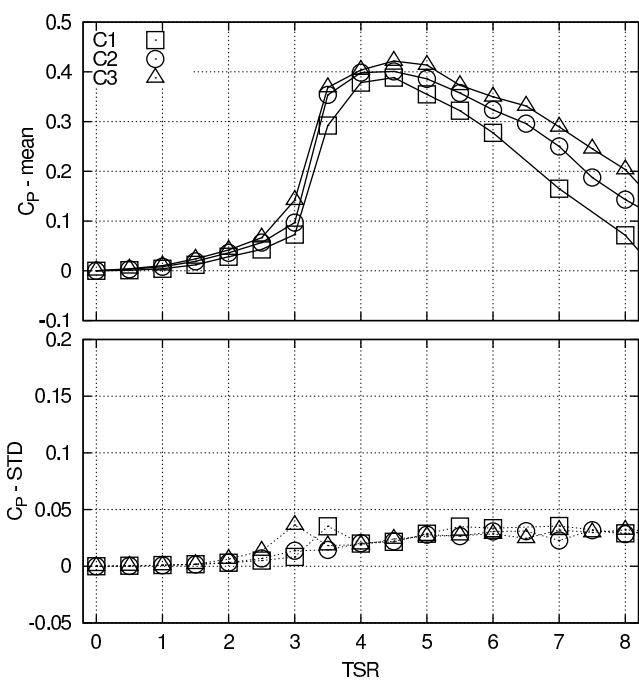

(a) Power coefficient

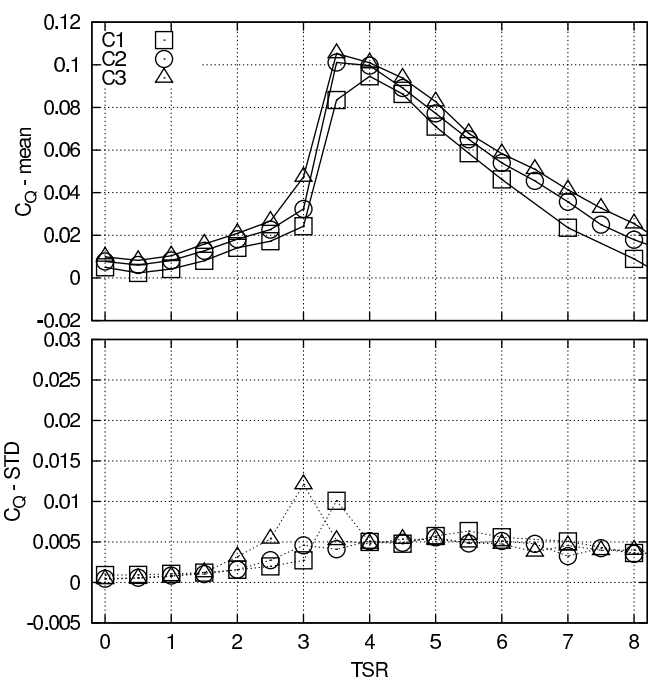

(b) Torque coefficient

Figure 8: Power and torque coefficients - current only

The evolution of the torque coefficient (figure $8 \mathrm{~b}$ ) is quite similar to the power coefficient. It reaches a peak for $T S R$ between 3.5 and 4 for configuration $\mathrm{C} 1$, which is lower than the $T S R$ at the maximum of $C_{P}$. This peak is more pronounced than for the $C_{P}$.

For TSR greater than 4, the decrease of the torque coefficient is constant and steady. Again, slight differences appear for the highest TSR and the higher the velocity, the higher the $C_{Q}$. 
Similarly to the $C_{P}$, the standard-deviation of the torque coefficient is very low and remains below or equal to $1 \%$ for every $T S R$ and velocity.

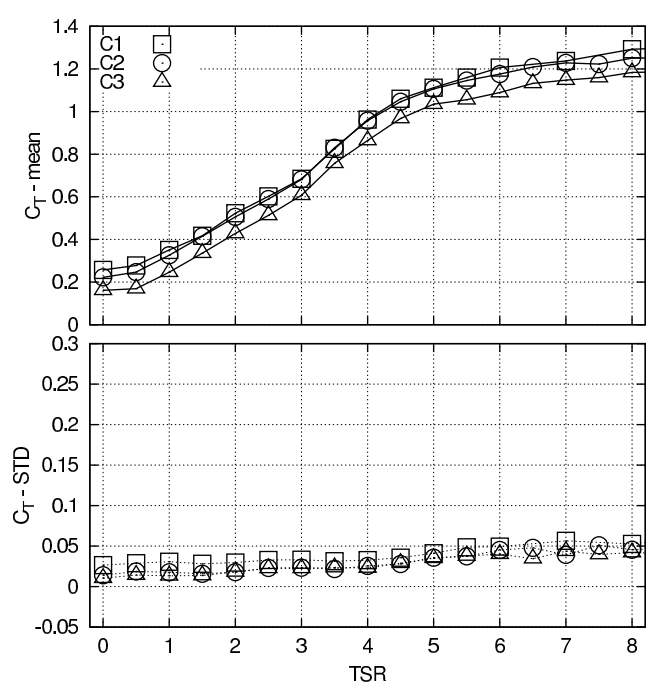

(a) Thrust coefficient
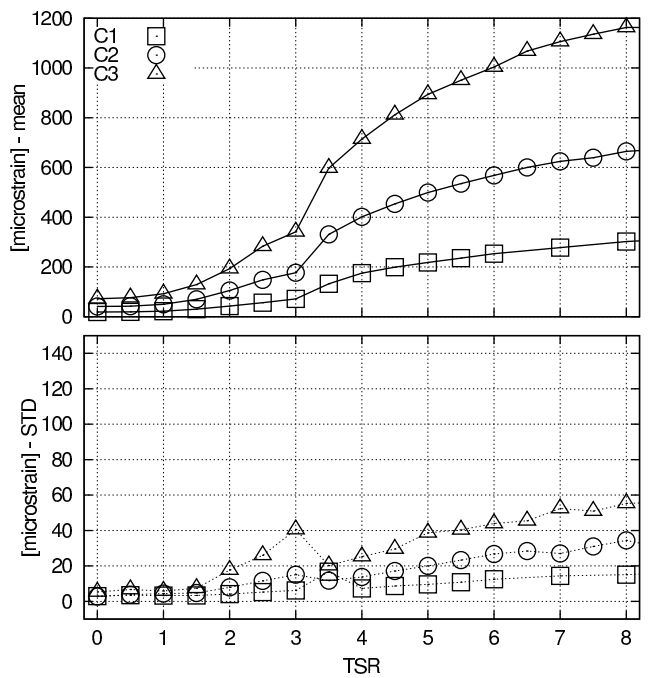

(b) Blade deformation

Figure 9: Thrust coefficient and blade deformation - current only

Contrary to the power and torque coefficients, the thrust coefficient (figure 9a) is always increasing with the $T S R$. This result may appear surprising, because it is different from previous results with the same shape of blade [13], where the $C_{T}$ also shows a maximum. However, the blades tested here are equipped with strain gauges and their surfaces are rougher than the ones tested in [13]. These two parameters decrease the lift produced by the blades and increase their drag. This is the main reason why the total drag continuously increases with the $T S R$ even for the greater values, where the slope of the curve decreases. Moreover, the pitch angle was close to zero which also limits the production of lift force.

It is interesting to note that the curve obtained with the C3 configuration is always slightly lower than the two others. Except for this small difference, all curves are very close to each other.

The standard-deviation of this coefficient is also very low, as for the power and torque. It represents less than $5 \%$ of the mean value for every $T S R$ and velocity. 
The dimensional mean blade strains observed on figure $9 \mathrm{~b}$, show also a constant increase. These strains are increasing with the $T S R$ but also with the current velocity. As for the power and torque coefficients, a sudden jump is visible on these curves between $T S R=3$ and 3.5, with a sudden increase of the deformation.

The standard-deviation of the blade deformation is increasing slightly with the TSR but remains lower or equal to $5 \%$ of the mean value for every velocity.

Only one curve by case is presented here even though one curve for each blade was recorded. In order to prevent overloading the figure end due to the quasi-identical answers of the three blades, only the mean and the standarddeviation are given for all the studied cases.

\subsection{Response under wave and current loads}

The plots shown in this section are the same as those for the current alone, but correspond to the cases of wave and current. On these graphs, the configuration $\mathrm{C} 2$ - for current alone, but with quite the same velocity as the cases with waves and current - is added to help to compare the results obtained.

For every curve presented on the following figures 10a, 10b, 11a and 11b, it is remarkable how the mean coefficients and strains are close to each other. No differences appear for the mean values between the different wave cases and the $\mathrm{C} 2$ case. However,the standard-deviation curves are quite different from the pure current case.

From $T S R$ greater or equal to 2.5 the fluctuating part of the power and torque coefficients becomes really high (figure 10a and 10b). For the torque coefficient, the standard-deviation for $T S R \simeq 3$ is even the highest value of the range, with about 0.02 whereas the mean value is "only" about 0.06 . This high fluctuating part (33\% of the mean part) highlights that this $T S R$ is a key-point between a lower branch $(T S R<3)$ and an upper branch $(T S R \geq$ 3.5) of the curve.

For greater $T S R$, the fluctuating part of these coefficients stays high for the wave cases. It continues to increase for the power coefficients whereas it slightly decreases from $T S R=5$ for the $C_{Q}$.

For the $C_{P}$ and $C_{Q}$ coefficients, this standard-deviation value stays low at first, as for the pure current case, for $T S R<3$. Then, from $T S R \geq 3$, it increases until a quite high value compared to the mean and stays high. It 


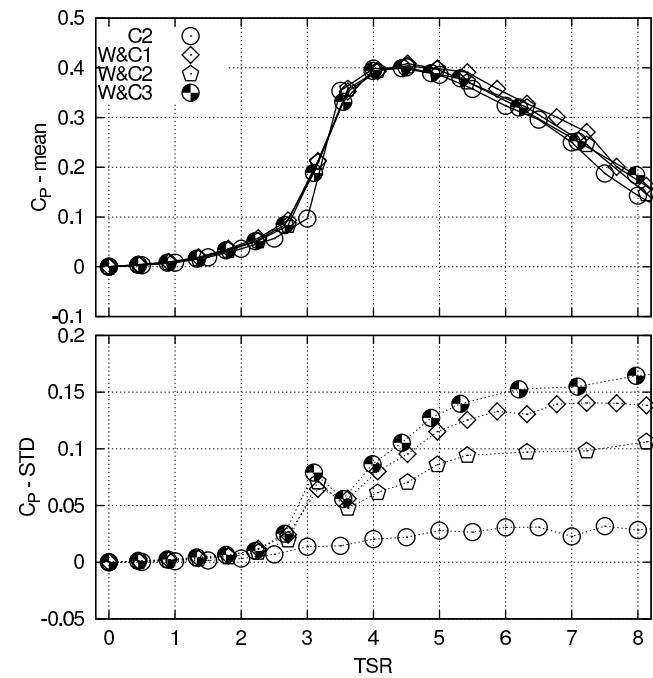

(a) Power coefficient

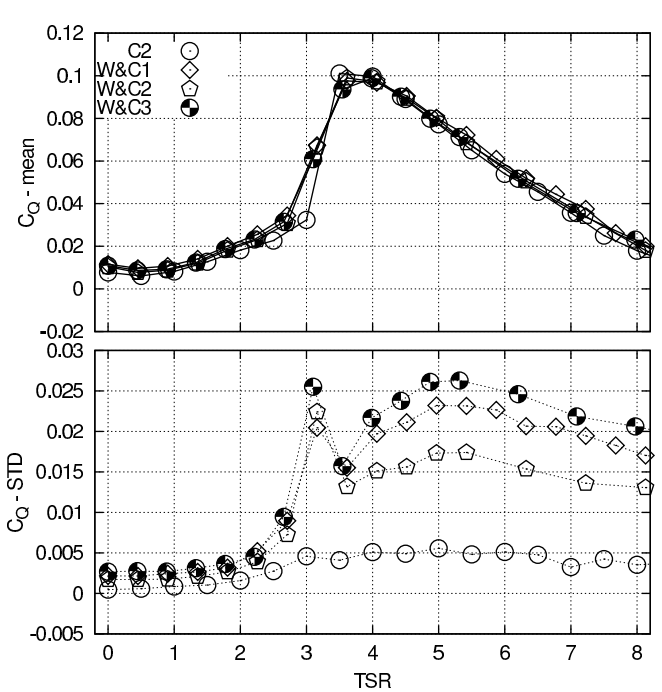

(b) Torque coefficient

Figure 10: Power and torque coefficients - current and wave

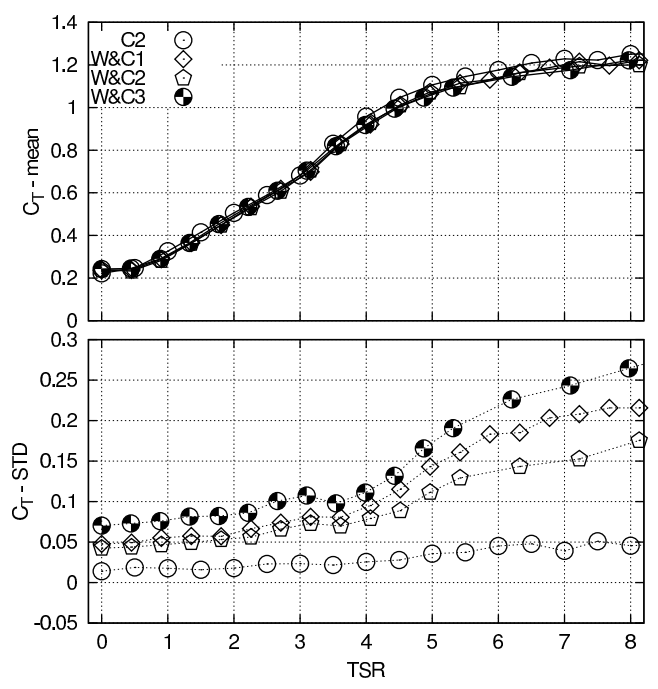

(a) Thrust coefficient

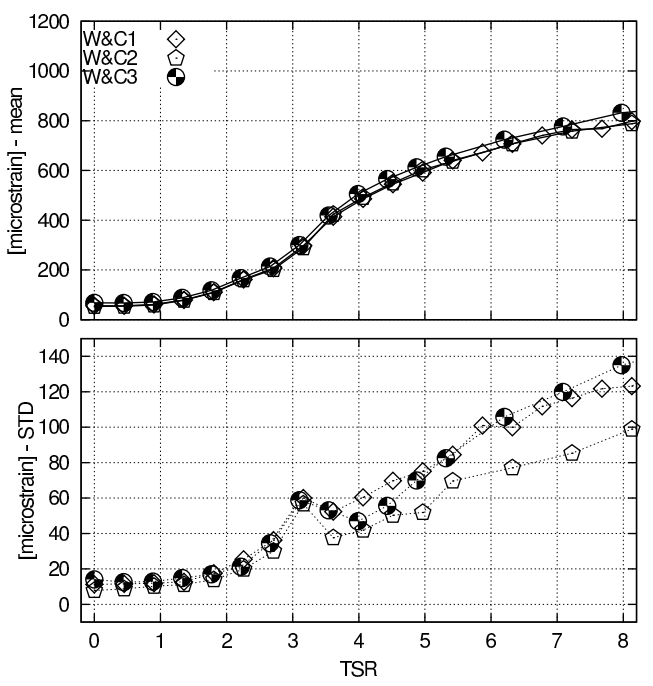

(b) Blade deformation

Figure 11: Thrust coefficient and blade deformation - current and wave

is interesting to note that this fluctuating part, which comes from the waves and the increase of the turbulence intensity $I_{\infty}$, is not constant for a given case but changes with the TSR. 
Results are slightly different for the thrust coefficient (figure 11a) because the fluctuating part is higher than for the $\mathrm{C} 2$ case from the first $T S R$. It increases smoothly until the highest $T S R$ with values 4 to 5 times higher than the C2 case.

Concerning the blade strains (figure 11b), the $\mathrm{C} 2$ case is not shown with the wave cases because these results are dimensional. Because of the velocity differences, it is difficult to compare the cases with each other. However, the standard-deviation values are always increasing with the $T S R$. Moreover, they are really high: from 50 to 150 microstrain for $T S R>5$, compared to the previous cases without waves (figure $9 \mathrm{~b}$ ) where the deformation stays lower or equal to 50 microstrain for every $T S R$ and higher velocities.

By comparing the standard-deviation values between the three wave cases, it is interesting to note that for each coefficient and blade strain, W\&C3 are the highest then come $\mathrm{W} \& \mathrm{C} 1$, and $\mathrm{W} \& \mathrm{C} 2$ are the lowest. This result is not surprising because the W\&C3 case shows the largest wave orbital velocities and turbulence intensity (figure 7). These fluctuating characteristics are higher than for the W\&C1 case, excepted for $u_{\text {orb }}$ in the lower part of the turbine. W\&C2 case is minimal in terms of $I_{\infty}$ and $u_{\text {orb }}$.

These results underline the importance of turbulence intensity and wave effects on both mean and especially standard-deviation of all the turbine and blade characteristic parameters. In the next section, we analyse the wave effects in terms of frequency response.

\subsection{Time history and frequency analysis}

In this section we mainly focus on the differences observed between the pure current case $\mathrm{C} 2$ and the wave and current cases. In order to understand and explain where the fluctuating part noted in the previous section comes from we examine the time history and analyse the frequencies of the torque, drag force and blade deformation recorded at $T S R=4$.

On figure $12 \mathrm{a}$ and $12 \mathrm{~b}$ the time history and Fast Fourier Transform (FFT) of the corresponding signal for the $\mathrm{C} 2$ case are presented. For torque and drag force signals, no frequency appears on the FFT except for the lowest frequencies (noise essentially) and at three times the rotation frequency $(2.55 \mathrm{~Hz})$ but with a very low and wide amplitude. However, this last frequency is also noted on the time history plots. 


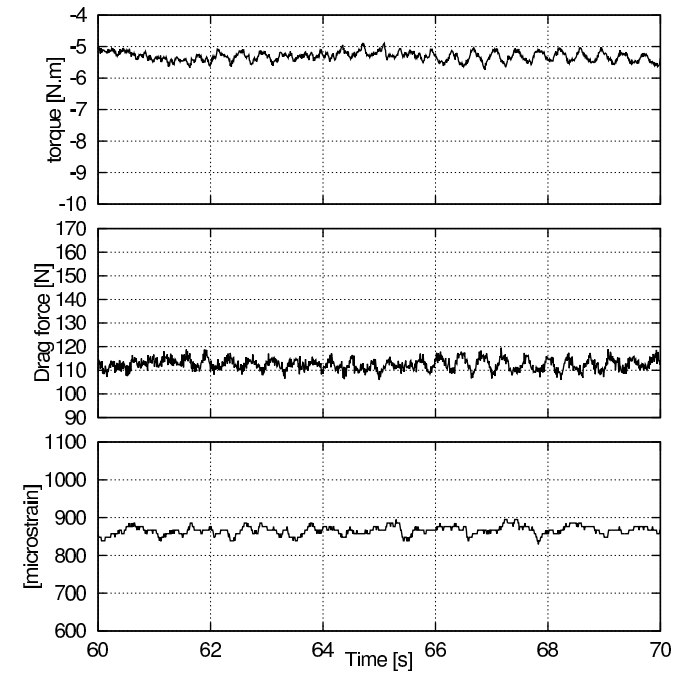

(a) Time history

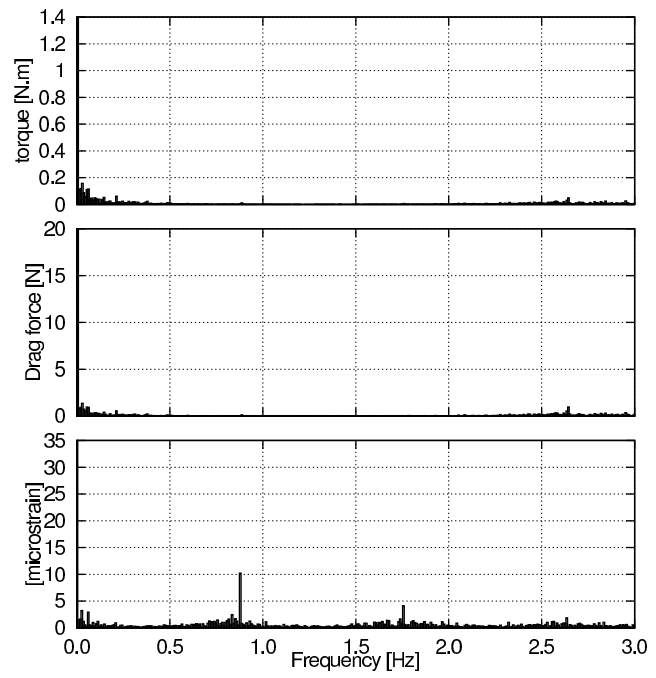

(b) Frequency spectrum

Figure 12: Time history and frequency spectrum - current only: C2 case at $T S R=4\left(f_{r}=0.85 \mathrm{~Hz}\right)$

For the blade deformations, the rotation frequency $f_{r}=0.85 \mathrm{~Hz}$ shows the highest amplitude with 10 microstrain before harmonics $1(1.7 \mathrm{~Hz})$ and 2 $(2.55 \mathrm{~Hz})$.

On figures $13 \mathrm{a}$ and $13 \mathrm{~b}$ the wave frequency $(0.5 \mathrm{~Hz})$ is the main frequency noted on the spectra of torque and drag force. No other frequency appears.

On the other hand, the blade strain spectrum shows the highest frequency at the rotation frequency $(0.85 \mathrm{~Hz})$ with an amplitude more than 1.5 times higher than the wave frequency $(0.5 \mathrm{~Hz})$. First harmonics of the rotation and wave frequencies can be seen at $1.7 \mathrm{~Hz}$ and $1.0 \mathrm{~Hz}$ respectively but with lower amplitudes. Another frequency of the same amplitude is also visible at $0.425 \mathrm{~Hz}$ which is half the rotation frequency.

It is interesting to compare the strain spectra obtained for the $\mathrm{C} 2$ (figure $12 \mathrm{~b}$ ) and $\mathrm{W} \& \mathrm{C} 1$ (figure 13b) cases. In contrast to the torque and drag force spectra where the only main difference is the wave frequency, the amplitude of the rotation frequency is increasing for the deformation from 10 microstrain for the $\mathrm{C} 2$ case to more than 25 microstrain for the W\&C1 case.

In this case, the blade deformation part coming from the rotation is even higher than the contribution from the waves. 


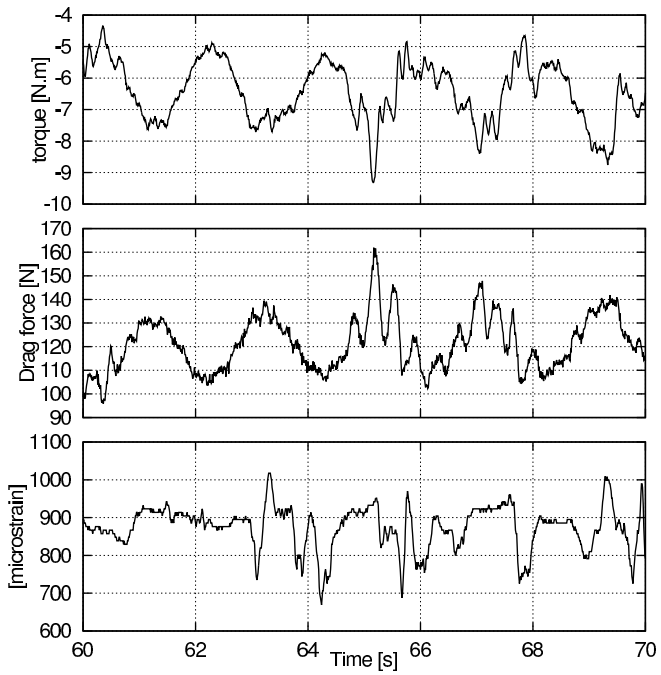

(a) Time history

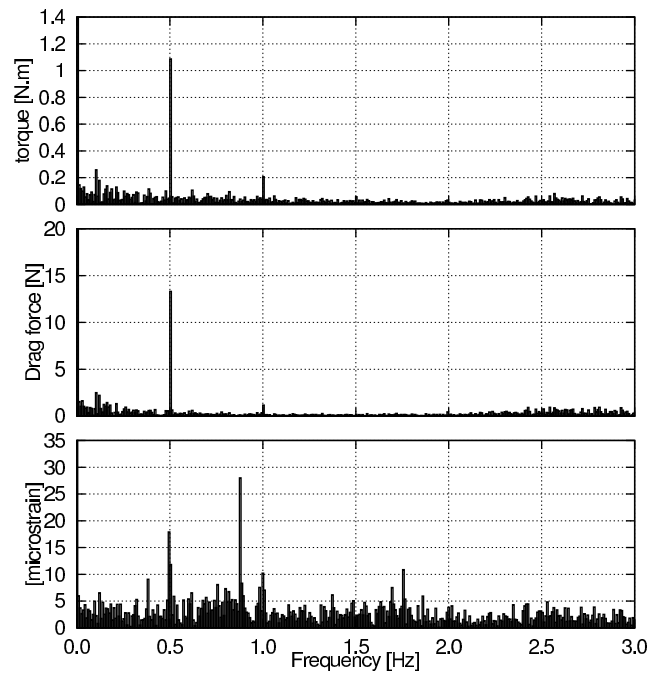

(b) Frequency spectrum

Figure 13: Time history and frequency spectrum - wave and current: W\&C1 case at $T S R=4\left(f_{r}=0.85 \mathrm{~Hz}\right)$

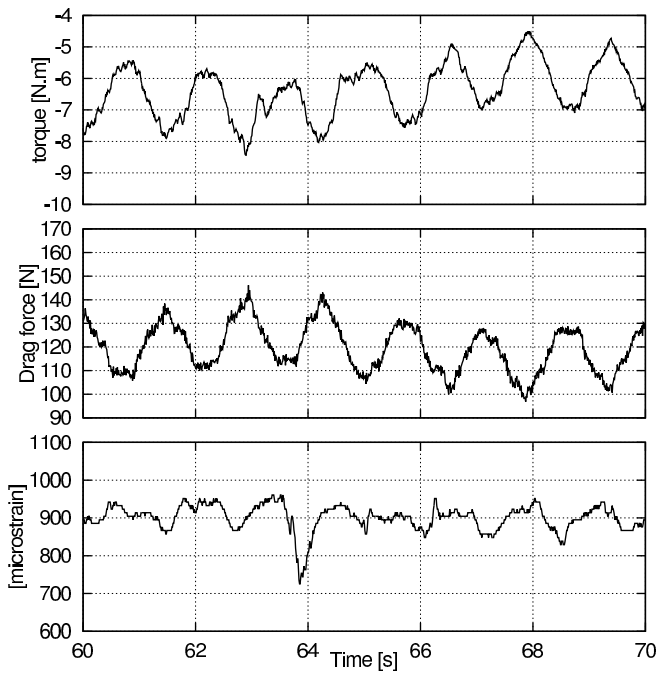

(a) Time history

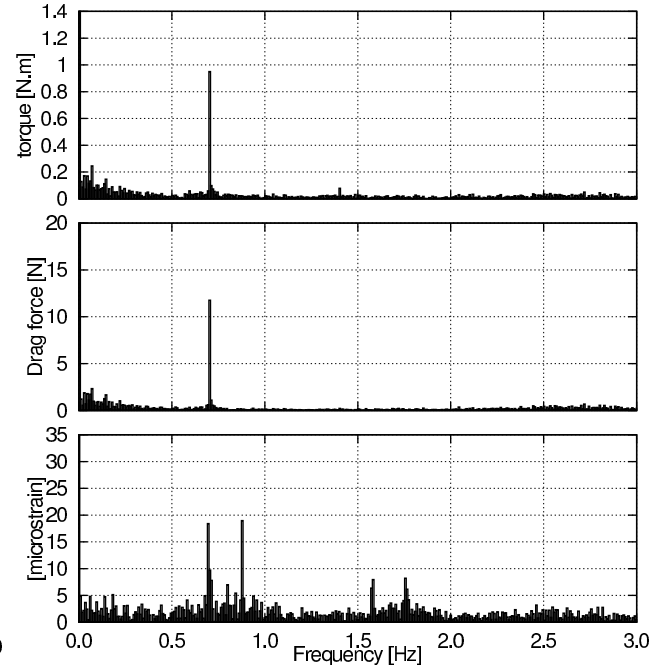

(b) Frequency spectrum

Figure 14: Time history and frequency spectrum - wave and current: W\&C2 case at $T S R=4\left(f_{r}=0.85 \mathrm{~Hz}\right)$ 
On the figure $14 \mathrm{a}$ and $14 \mathrm{~b}$, for the $\mathrm{W} \& \mathrm{C} 2$ case, the wave frequency is $0.7 \mathrm{~Hz}$. Again, only the wave frequency appears on the torque and drag force spectra. The amplitudes of these peaks are slightly lower than for the W\&C1 case with about $10 \%$ differences, whereas the amplitudes of the waves are constant ( $80 \mathrm{~mm}$ for both cases).

For the blade deformation spectrum, the wave peak at $0.7 \mathrm{~Hz}$ shows about the same amplitude as for the previous case at $0.5 \mathrm{~Hz}$. However, the rotation peak $(0.85 \mathrm{~Hz})$ is slightly lower with less than 20 microstrain compared to more than 27 microstrain previously.

Harmonic 1 of the rotation frequency at $1.7 \mathrm{~Hz}$ is noticeable on this spectrum and so is the $1.55 \mathrm{~Hz}$ frequency. This latter frequency is the consequence of the resonance phenomena between the two main frequencies of wave and rotation: $0.7+0.85=1.55 \mathrm{~Hz}$.

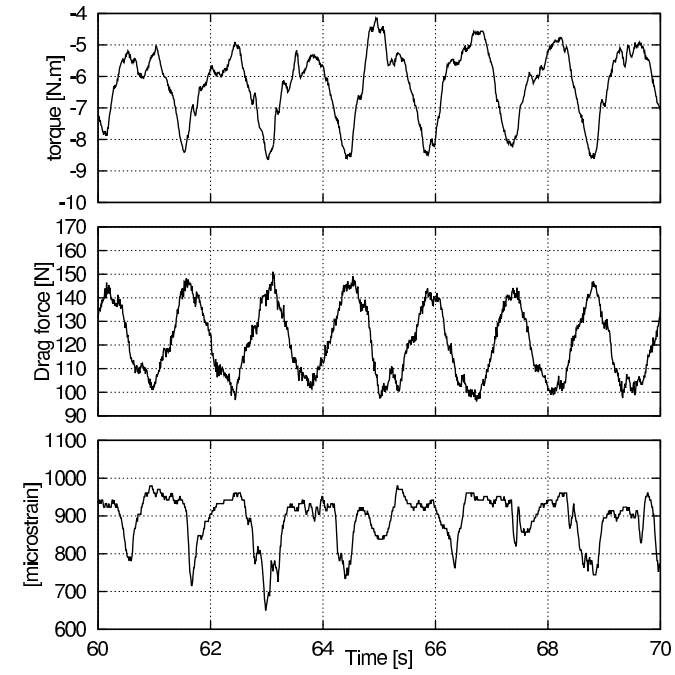

(a) Time history

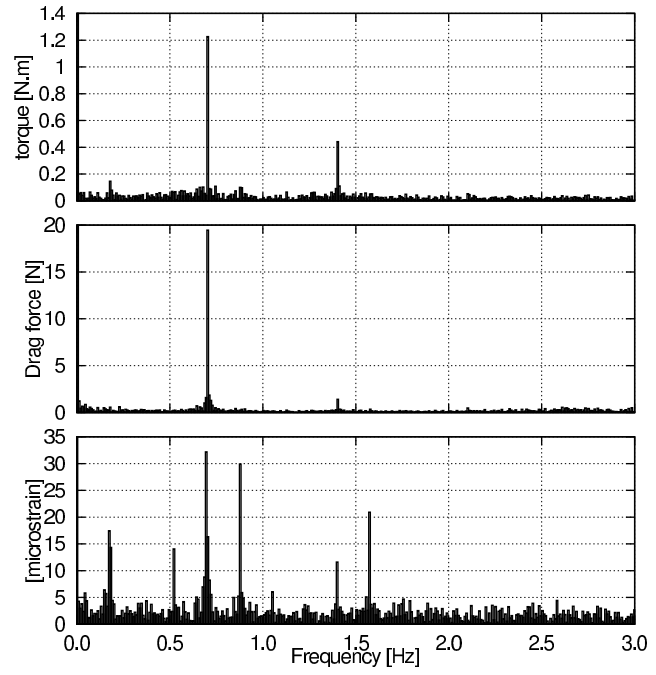

(b) Frequency spectrum

Figure 15: Time history and frequency spectrum - wave and current: W\&C3 case at $T S R=4\left(f_{r}=0.85 \mathrm{~Hz}\right)$

Figure $15 \mathrm{a}$ and $15 \mathrm{~b}$ show the same results but for the W\&C3 case with waves at $0.7 \mathrm{~Hz}$ but with a higher amplitude. The results are slightly different from the previous ones with the wave frequency and its first harmonic especially on the torque but also on the drag force spectra. The amplitudes of these peaks at $0.7 \mathrm{~Hz}$ are higher than the previous one with more than 
$1.2 \mathrm{~N} . \mathrm{m}$ for the torque compared to less than $1 \mathrm{~N} . \mathrm{m}$ for the W\&C2 case and $20 \mathrm{~N}$ for the drag compared to about $12 \mathrm{~N}$ previously.

For the blade deformations, many peaks appear on the spectrum. The wave frequency is easily recognizable at $0.7 \mathrm{~Hz}$ with the highest amplitude: more than 30 microstrain. These deformations are 1.75 times higher than those observed for the previous case. The only difference between these two cases are the amplitude of the wave: $80 \mathrm{~mm}$ for the W\&C2 and $140 \mathrm{~mm}$ for the W\&C3, so 1.75 times higher for this last case. The wave part of the fluctuations of the blade deformations seems to be directly linked with the amplitude.

Just under this first peak is the rotation peak with a little less than 30 microstrain at the frequency of $0.85 \mathrm{~Hz}$. In contrast to the two previous cases, this rotation peak is slightly lower than the wave peak.

The first harmonic of the wave frequency is also noticeable on the spectrum at $1.4 \mathrm{~Hz}$ with amplitude higher than 10 microstrain.

As for the previous case, the resonance phenomena between the wave and rotation frequencies is visible at $1.55 \mathrm{~Hz}$ with a quite high amplitude, higher than 20 microstrain. This is revealed here also with the envelope frequency at $0.85-0.7=0.15 \mathrm{~Hz}$ with a relatively high amplitude of 16 microstrain.

Two other frequencies appears on this spectrum at $0.52 \mathrm{~Hz}$ with about 15 microstrain and its first harmonic at $1.05 \mathrm{~Hz}$ with just more than 5 microstrain. It is difficult to understand where they come from, because they only appear for this particular case.

Time-frequency spectrum analysis shows that fluctuating blade loads come essentially from waves, rotation speed and fluid/structure interactions. It will be interesting to compare these results with results obtained under irregular wave and current loads.

\section{Discussion}

Contrary to results given on figures $9 \mathrm{~b}$ and $11 \mathrm{~b}$, the blade deformations shown in figure 16 are presented in a non-dimensionalised form based on the square of the velocity. For the current and wave and current solicitations, all the mean strain results are superposed, indicating that they are mainly dependent on the square of the velocity.

Apart from the turbulence intensity which is higher for the wave and current cases (figure 7a), it appears that there is no difference between the 


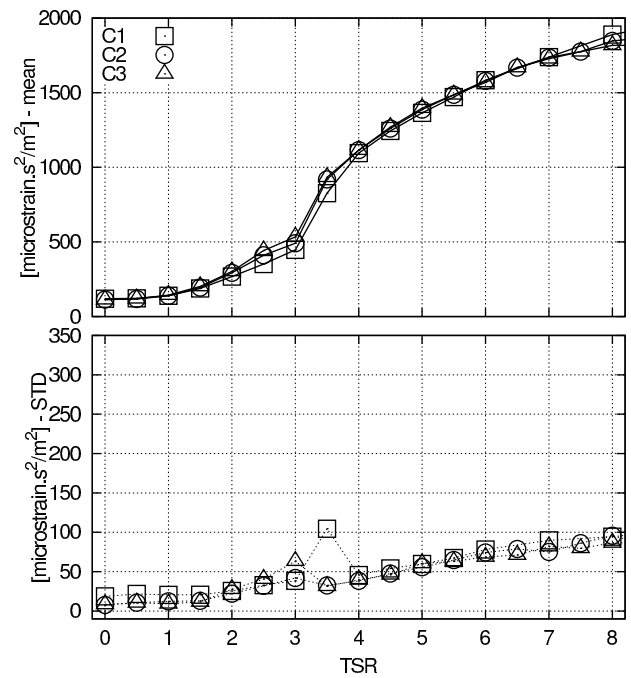

(a) Current only

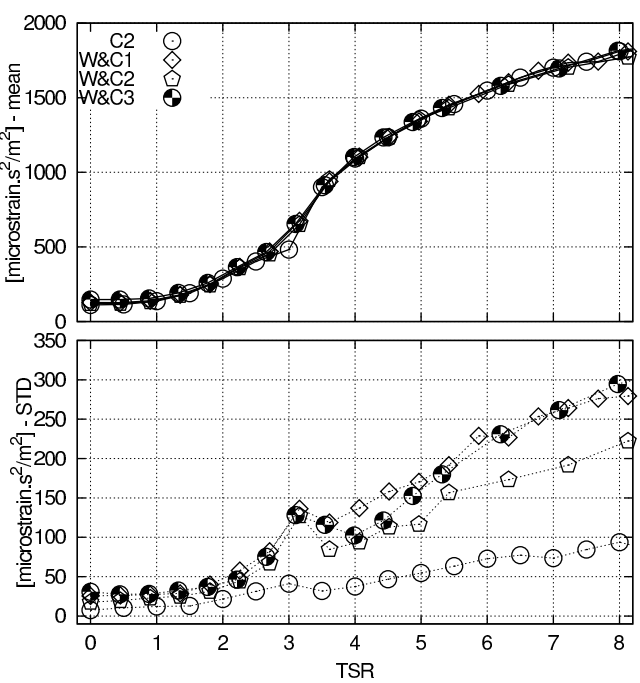

(b) Wave-current

Figure 16: Reduced blade strains

wave and current and the current alone cases, for the mean of the blade strains. This is absolutely not the case for the standard-deviations of the signals, where the wave and current cases show much higher values. This difference is of the order of 2 to 3 times higher than for the current alone cases. For example at $T S R=6$, the standard-deviation of the strains represents less than $5 \%$ of the mean for the current case, whereas it represents more than 10 to $15 \%$ of the mean for the wave and current cases. This can lead to premature fatigue damage of the blades.

To better understand this last point, the ratio between the standarddeviation over the mean of the strains is plotted versus the TSR for the wave and current tests on the figure 17 .

As noticed previously, this ratio is 2 to 3 times higher for cases with wave and current, for every $T S R$. Moreover, it is interesting to observe that this ratio is not constant but follows the same evolution with the TSR for both types of conditions. In fact, it is slightly higher for the lower $T S R$ until $T S R=3$. Then, for the highest $T S R$, the values are lower. For the wave and current cases, this ratio is from 12 to more than $20 \%$ for $T S R$ lower or equal to 3 and between 8 and $16 \%$ for $T S R$ greater to 3 . This is the same for the $\mathrm{C} 2$ case, but with lower values. 


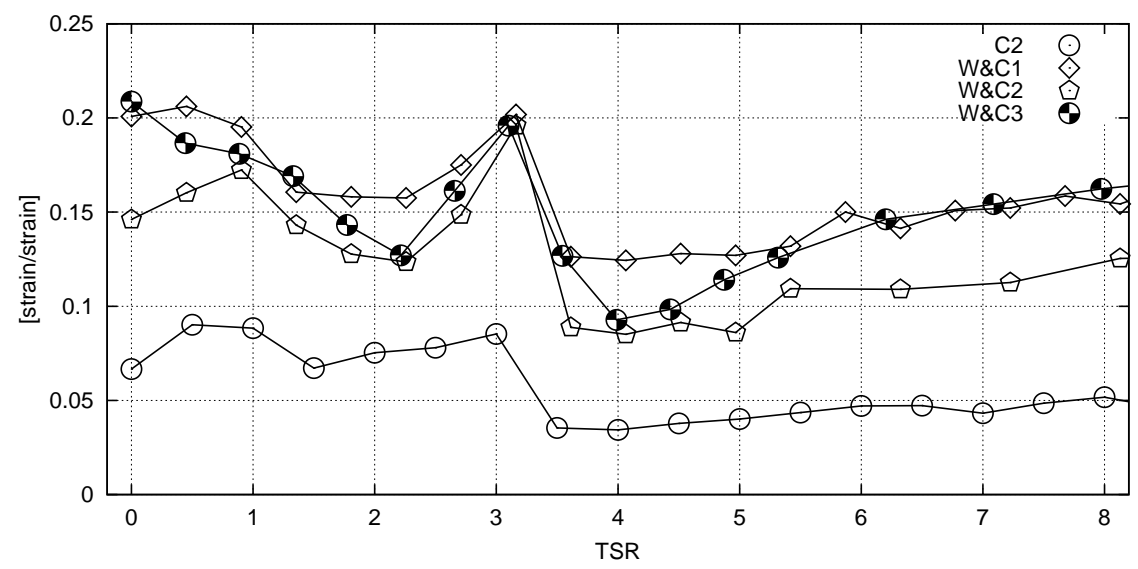

Figure 17: Ratio between the standard-deviation and the mean of the blade strains

The value obtained for $T S R=3$ looks surprising because all wave and current cases are superposed whereas they show a disparity before and after this TSR. In addition, the value obtained for this point is one of the highest with about $20 \%$ for the wave and current cases and $8 \%$ for the pure current case. In contrast to the high values obtained for the lowest $T S R$, where the mean is low and so the ratio is high, for $T S R=3$, it is the standard-deviation which is relatively high compared to the mean, as seen on figure $16 \mathrm{~b}$.

In fact, this point is a transition point between two different parts of the curves, as noted in the previous section for the power and torque coefficients. For many curves previously shown, a lower branch and an upper branch are distinguishable. So, for $T S R=3$, the standard-deviation is often high, indicating that there is a high fluctuating part for the corresponding value which "hesitates" between the lower and the upper branches of the curve. This characteristic can be seen on figures $8 \mathrm{a}, 8 \mathrm{~b}, 10 \mathrm{a}$ and $10 \mathrm{~b}$ but also on the blade strains on figures $9 \mathrm{~b}$ and $11 \mathrm{~b}$. Before this point the mean values of the corresponding parameters are often low, this is the lower branch. For $T S R=3$, these values increase suddenly and the standard-deviation shows a peak most of the time. For higher $T S R$, the mean values are higher, this is the upper branch. For the wave and current cases especially, the standarddeviation of the signal for the upper branch is also very high.

These two branches are not so visible for the thrust coefficient. For the pure current cases (figure 9a), there are no changes between, before and 
after $T S R=3$. However, for the wave and current cases (figure 11a), the standard-deviation is increasing strongly from $T S R=4$, but there is no corresponding increase for the mean values.

As explained in the previous section, in a similar study Mycek [13] shows a thrust coefficient which goes though a maximum at about $T S R=5$ then decreases. Here, the thrust coefficient is always increasing and so are the strains. In this particular case, the pitch angle is close to zero and the surface of the blades is rather rough and non-homogeneous due to the strain gauges. For this reason the lift produced by the rotation of the three blades stays low and never compensates the drag force, so the $C_{T}$ and the strains are always increasing with the TSR.

However, a new study with a different pitch angle is necessary to check first if the $C_{T}$ goes through a maximum and then, if the strains follow the same profile. Before this future work, it is interesting to look at the ratio between the blade strains and the turbine drag force $T$ versus the TSR and the velocities. Figure 18 shows the result obtained for this ratio, for the pure current cases.

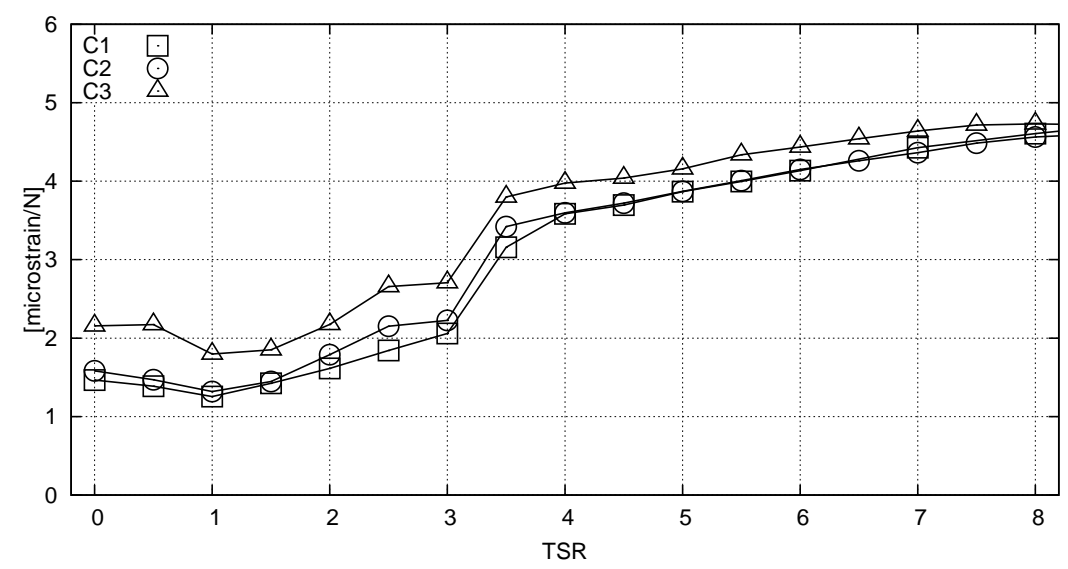

Figure 18: Ratio between the mean of the blade strains over the mean of the drag force applied on the turbine

On this figure, it is noticeable that the ratio is quite constant with the current velocity. The curves are superposed, except for the C3 case which show values slightly higher. This difference comes mainly from the drag force which shows lower values for the C3 case (figure 9a).

When plotted versus the TSR, this curve also shows the two branches: 
lower and upper, with the transition point at $T S R=3$. For the lower $T S R$, the ratio is quite constant and lower than 3. For $T S R$ greater or equal to 3.5 , the ratio increases slightly from values between 3 to 4 to values around 4.5. This means that for the lower rotation speeds, the blade strains are of the order of twice the drag force. For higher rotation speeds, the strains are about 2 times higher, at about 4 times the drag force.

In term of blade tip displacement, these results highlight values of about $2 \%$ of the blade radius (corresponding to a tip displacement of $10 \mathrm{~mm}$ ) with fluctuations higher than $2 \mathrm{~mm}$. These values may seem relatively low but they are to be related to the characteristics of the blades and principally to the steel axis which is not representative of a real blade characteristics. A comparison with real data is necessary to be able to extrapolate these results at a real scale.

This result has to be confirmed and extended for different pitch angles and eventually to a case where the $C_{T}$ goes though a maximum, such as in [13]. Another point to be examined is the influence of blade stiffness and surface roughness. Some preliminary tests have been performed on blades made of polymer tested with and without glass fibre reinforcement surface coatings [20]. Such studies are essential in order to relate flume tank results to full size blade behaviour

\section{Conclusion}

Ensuring the long term durability of ocean energy structures is a key element in the development of cost-effective industrial system such as marine current turbines. The combined experience of composite boats and composite wind turbine blades has led to a common belief that composites can be used in marine turbine blades without further development. However, coupling between sea water diffusion, ageing processes and high mechanical loads can results in very severe loading conditions, which must be fully investigated if costly failures at sea are to be avoided.

An experimental facility has been developed enabling prototype tidal turbine blade concepts to be studied before expensive sea trials. Tests were performed on a $1 / 20$ scale tidal turbine with strain gauge instrumented polymer blades. The test results under current alone then wave and current loading emphasize the strong influence of waves on the loading of turbine blades. 
The cyclic amplitude is directly related to wave conditions. These results indicate that in order to design blades it is not sufficient to consider only current loads, fatigue performance will be dominated by the wave contribution so detailed knowledge of both wave and current conditions is essential. A comparison with irregular wave and current conditions could be interesting in order to analyse the blade behaviour for a combination of frequencies. An equivalent analysis at a higher flow turbulence intensity level (of the order of $20 \%$ ) will also be very useful. These wave and current interactions cannot be neglected in the design of tidal turbine systems, and must be fully understood if failures in service are to be avoided.

\section{Acknowledgements}

The authors gratefully acknowledge the contributions of A. Kerboul, J. V. Facq and T. Bacchetti to the work presented here.

\section{References}

[1] European Commission, Ocean Energy Conversion in Europe, Tech. rep., Centre for Renewable Energy Resources (2006).

[2] UK House of Commons Energy and Climate Change Committee, The Future of Marine Renewables in the UK, Tech. rep., HC1264 (2012).

[3] M. J. Khan, G. Bhuyan, M. T. Iqbal, J. E. Quaicoe, Hydrokinetic energy conversion systems and assessment of horizontal and vertical axis turbines for river and tidal applications: A technology status review, Applied Energy 86 (10) (2009) 1823-1835.

[4] A. S. Bahaj, Generating electricity from the oceans, Renewable and Sustainable Energy Reviews 15 (7) (2011) 3399-3416.

[5] F. O. Rourke, F. Boyle, A. Reynolds, Tidal energy update 2009, Applied Energy 87 (2) (2010) 398-409.

[6] P. L. Fraenkel, Development and testing of Marine Current Turbine's SeaGen 1.2 MW tidal stream turbine, in: 3rd International Conference on Ocean Energy (ICOE), Bilbao, Spain, 2010. 
[7] OpenHydro Press Release, Nova Scotia Power and OpenHydro reach next project milestone (Dec. 2010).

URL http://www.openhydro.com/news/OpenHydroPR-171210.pdf

[8] F. Guinot, M. Le Boulluec, Realistic marine flow conditions for current turbines studies, in: 2nd International Conference on Ocean Energy (ICOE), Brest, France, 2008.

[9] I. Masters, J. A. C. Orme, J. Chapman, Towards realistic marine flow conditions for tidal stream turbine, in: 7th European Wave and Tidal Energy Conference (EWTEC), Porto, Portugal, 2007.

[10] A. S. Bahaj, A. F. Molland, J. R. Chaplin, W. M. J. Batten, Power and thrust measurements of marine current turbines under various hydrodynamic flow conditions in a cavitation tunnel and a towing tank, Renewable Energy 32 (3) (2007) 407-426.

[11] W. M. J. Batten, A. S. Bahaj, A. F. Molland, J. R. Chaplin, Experimentally validated numerical method for the hydrodynamic design of horizontal axis tidal turbines, Ocean Engineering 34 (7) (2007) 10131020 .

[12] F. Maganga, G. Germain, J. King, G. Pinon, E. Rivoalen, Experimental characterization of the effects on marine current turbine behaviour and on its wake properties, IET Renewable Power Generation 4 (6) (2010) 498-509.

[13] P. Mycek, B. Gaurier, G. Germain, G. Pinon, E. Rivoalen, Numerical and Experimental Study of the Interaction Between Two Marine Current Turbines, in: 9th European Wave and Tidal Energy Conference (EWTEC), Southampton, UK, 2011.

[14] P. Mycek, G. Pinon, B. Gaurier, G. Germain, E. Rivoalen, Numerical developments for the simulation of performances and wake of marine current turbines, in: 13èmes Journées de l'Hydrodynamique, Chatou, France, 2012.

[15] W. M. J. Batten, A. S. Bahaj, A. F. Molland, J. R. Chaplin, The prediction of the hydrodynamic performance of marine current turbines, Renewable Energy 33 (5) (2008) 1085-1096. 
[16] L. Myers, A. S. Bahaj, Scale reproduction of the flow field for tidal energy converters, in: 10th World Renewable Energy Congress (WREC), Glasgow, UK, 2008.

[17] L. Myers, A. S. Bahaj, Near wake properties of horizontal axis marine current turbines, in: 8th European Wave and Tidal Energy Conference (EWTEC), Uppsala, Sweden, 2009.

[18] L. E. Myers, A. S. Bahaj, Experimental analysis of the flow field around horizontal axis tidal turbines by use of scale mesh disk rotor simulators, Ocean Engineering 37 (2-3) (2010) 218-227.

[19] Y. L. Young, Fluid-structure interaction analysis of flexible composite marine propellers, Journal of Fluids and Structures 24 (6) (2008) 799818.

[20] P. Davies, G. Germain, B. Gaurier, A. Boisseau, D. Perreux, Evaluation of the durability of composite tidal turbine blades, Philosophical Transactions of the Royal Society A (2012) accepted for publication.

[21] G. Germain, Marine current energy converter tank testing practices, in: 2nd International Conference on Ocean Energy (ICOE), 2008.

[22] G. Germain, A. S. Bahaj, C. Huxley-Reynard, P. Roberts, Facilities for marine current energy converter characterization, in: 7th European Wave and Tidal Energy Conference (EWTEC), Porto, Portugal, 2007.

[23] G. Pinon, P. Mycek, G. Germain, E. Rivoalen, Numerical simulation of the wake of marine current turbines with a particle method, Renewable Energy 46 (2012) 111-126.

[24] F.-Z. Tai, K.-W. Kang, M.-H. Jang, Y.-J. Woo, J.-H. Lee, Study on the analysis method for the vertical-axis wind turbine having Darrieus blades, Renewable Energy article in press.

[25] M. A. Sayed, H. A. Kandil, A. Shaltot, Aerodynamic analysis of different wind-turbine-blade profiles using finite-volume method, Energy Conversion and Management 64 (2012) 541-550. 